\title{
Identification of the Phytochemical Compounds and Their Type I Procollagen Induction in Astragalus membranaceus Sprouts Grown under Different Light Conditions
}

\author{
Seon Young Jeong, Mi Yeon Moon, Eun Kyung Ryu, Je Sung Lee, Joonseok Cha* \\ Research Center, The Garden of Naturalsolution, Osan-si, Gyeonggi-do, 18103, Republic of Korea.
}

\begin{tabular}{l}
\hline ARTICLE INFO \\
\hline Article history: \\
Received on: $02 / 03 / 2018$ \\
Accepted on: $22 / 04 / 2018$ \\
Available online: $29 / 06 / 2018$
\end{tabular}

\section{Key words:}

A. membranaceus sprout, hwanggi, tryptophan, type 1 procollagen.

\begin{tabular}{l}
\hline ABSTRACT \\
\hline Astragalus membranaceus, a medicinal herb, has been used for diuretic, tonic, anti-viral and antioxidant effects. Its \\
root is widely used in Chinese and Korean traditional medicines, but in this study, the sprout grown optimally in our \\
indoor system was evaluated for cosmetic efficacies. Interestingly, A. membranaceus sprout extract activated the \\
production of type I procollagen by human dermal fibroblast cells in a dose-dependent manner, without showing cell \\
toxicity. A phytochemical study was conducted to identify the active constituents in the extract by solvent fractionation \\
and column purifications. As a result, three compounds: tryptophan (1), linoleic acid (2) and adenine (3) were identified \\
by NMR spectroscopy. Isolated tryptophan was verified to induce the synthesis of the type I procollagen in a dose- \\
dependent manner. These results demonstrate that $A$. membranaceus sprouts containing tryptophan can be developed \\
as skin care ingredient with the optimization of indoor cultivation system.
\end{tabular}

\section{INTRODUCTION}

Astragalus membranaceus (Fisch.) Bge is an annual or perennial herb in the Leguminosae family and called milkvetch root (English), huangqi (Chinese), ogi (Japanese), or hwanggi (Korean) (Ma et al., 2000). It is an important medicinal plant in Korea and China. Hwanggi root has been traditionally used for draining pus, reducing pain, treating leprosy, boosting immunity, recovering from fatigue and alleviating skin diseases (Tzu et al., 2014). It has been known to contain saponins, cycloastragenols, and polysaccharides. A group of cycloastragenol (CAG) such as an aglycone of acetylastragaloside I, isoastragalosides and astragalosides, has been reported (Luo et al., 2016) and more than 40 saponins have been reported from hwanggi root (Ren et al., 2013). More recently, new saponins from hwanggi root were reported: astrolano-saponin A1, A2, B, C, D, and E (Wang et al., 2016).

\footnotetext{
${ }^{*}$ Corresponding Author

Joonseok Cha, Research Center, The Garden of Naturalsolution, Osansi, Gyeonggi-do, 18103, Republic of Korea.

E-mail:jcha1@naturalsolution.co.kr
}

Astragalosides are known as active compounds having various pharmacological activities (Kwon et al., 2013). A number of studies reported cardiotonic (Zhang et al., 2006), anti-aging (Lei et al., 2003), anti-cancer (Cho et al., 2007), anti-allergy (Kim et al., 2013), and anti-inflammatory effects (Zhang et al., 2003). Moreover, glabridin, one of hwanggi peptides has been shown to inhibit expression of MMPs in human dermal fibroblasts, suggesting anti-wrinkle efficacy (Sun et al., 2014).

Anti-aging effects are critical for cosmetic ingredients. Aging is perceived by increased wrinkles and decreased elasticity of the skin. Wrinkle and skin elasticity depend upon the amount of collagen and elastin production in the extracellular matrix (ECM). Collagen accounts for $70-80 \%$ of the human dermis and collagen synthesis are vital to maintain youthful looking skin (Sher et al., 1997). Type I and III collagens are the major components of human dermis. Amount of Type I in normal skin is $80 \%$, while type III is $15 \%$. Hence, type 1 collagen is the major component of ECM and it is directly related to skin aging (Lovell et al. 1987). Collagen is degraded naturally by MMPs (matrix metalloproteinases), which are responsible for the physiological degradation of ECM proteins. Repeated 
exposure to sunlight causes skin damage by activating MMPs that breakdown collagens (Fisher et al., 2002) and stimulates tumor necrosis factor- $\alpha,-\gamma$, nitric oxide and interleukin, all of which inhibit the synthesis of collagen in the skin and increase the expression of collagen-degrading enzymes. These changes lead to photo-aging, skin erythema, roughness, wrinkles and blackening (Sher et al., 1997).

We have developed novel cosmetic agents derived from plants, especially sprouts cultivated in controllable conditions, such as safflower sprout extract (Chang et al., 2014) and peanut sprout extract (Mi, 2016). In this study, we cultivated hwanggi sprout by using previously reported cultivation system (Chang et al., 2014) and examined the collagen synthesis activation properties. In addition, the active constituents were identified by phytochemical investigations.

\section{MATERIALS AND METHODS}

\section{Plant materials and growth conditions}

Hwanggi seeds were purchased from Aramseed Co. (Seoul, Republic of Korea) in 2016. The seeds were kept at $5^{\circ} \mathrm{C}$ prior to use. Before germination, they were sterilized with $70 \%$ (v/v) ethanol for $3 \mathrm{~min}$ followed by $2 \% \mathrm{NaOCl}$ for $5 \mathrm{~min}$. After three washes, seeds were germinated in a room maintained at $20 \pm 2{ }^{\circ} \mathrm{C}$ with steady temperature and humidity controls. In two days, the germinated seeds were collected and exposed to different LED lights; red $(660 \mathrm{~nm})$, blue $(450 \mathrm{~nm})$, white $(5000$ k) or dark (no light) at $30 \sim 40 \mu \mathrm{mol} \cdot \mathrm{m}^{-2} \cdot \mathrm{s}^{-1}$ photosynthetic photon flux density (PPFD) and the daily photoperiod of 24 hours conditions constantly. They were watered 3 4 times daily, until harvest. The collected sprouts were dried in a $60^{\circ} \mathrm{C}$ oven for 24 hours. The dried sprouts were extracted with 1:20 extraction ratio (w/w) using 40\% 1, 3-propanediol (DuPont Tate \& Lyle) at $60^{\circ} \mathrm{C}$ for 24 hours. The extract was filtered and used for in vitro tests.
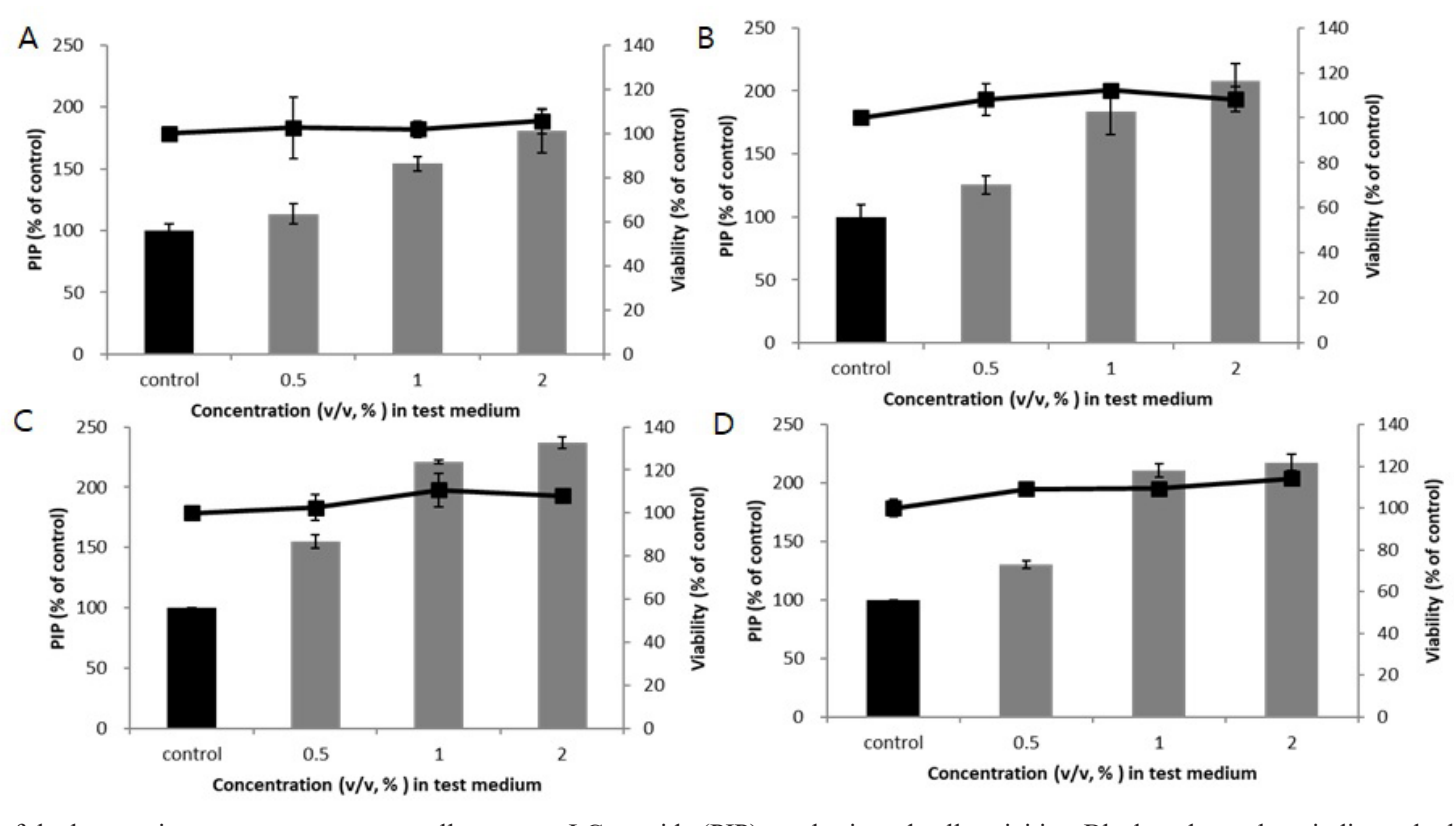

Fig. 1: Effect of the hwanggi sprouts extract on procollagen type I C-peptide (PIP) synthesis and cell toxicities. Black and grey bars indicate the levels of PIP and the

lines indicate cell viability. A, dark; B, white; C, red; D, blue.

\section{Chromatographic apparatus}

The high performance liquid chromatographic (HPLC) instrument (Agilent model 1200 series, Hewlett Packard, Palo Alto, CA, USA) equipped with a Kromasil C18 column $(5 \mu \mathrm{m} \times$ $4.6 \mathrm{~mm} \times 250 \mathrm{~mm}$ ), an autosampler, a photodiode array detector, and a vacuum degasser was used to analyze compounds of the extracts. The flow rate was at $1.0 \mathrm{ml} / \mathrm{min}$, and the detector was set at $320 \mathrm{~nm}$. For the HPLC analysis, a linear gradient of mobile phase (solvent A, $0.1 \%$ acetic acid in HPLC grade water; solvent B, HPLC grade acetonitrile) was used and the elution solvent was applied as follows: $90 \% \mathrm{~A} / 10 \% \mathrm{~B}$ at $0 \mathrm{~min}, 90 \% \mathrm{~A} / 10 \% \mathrm{~B}$ at $15 \mathrm{~min}, 60 \% \mathrm{~A} / 40 \% \mathrm{~B}$ at $30 \mathrm{~min}, 30 \% \mathrm{~A} / 70 \% \mathrm{~B}$ at $42 \mathrm{~min}, 5 \%$ $\mathrm{A} / 95 \% \mathrm{~B}$ at $44 \mathrm{~min}$, and $5 \% \mathrm{~A} / 95 \% \mathrm{~B}$ at $45 \mathrm{~min}$.

\section{Isolation of pharmacologically active components}

Hwanggi sprouts were harvested from the cultivation system (Chang et al., 2014), cleaned and dried at $60^{\circ} \mathrm{C}$ for 24 hours. The total extract was prepared from the dried sprouts (385 g) extracted in $50 \%(\mathrm{v} / \mathrm{v})$ ethanol for 24 hours at room temperatu re, followed by filtration. It was concentrated in a vacuum rotary evaporator (N-1100, Eyela Co., Tokyo, Japan). We obtained $81.6 \mathrm{~g}$ of ethanol extract from $385 \mathrm{~g}$ powdered sprout $(21 \%)$. To prepare the fractions, an aliquot of $81.6 \mathrm{~g}$ was re-suspended in $1 \mathrm{~L}$ of distilled water and serially fractionated with $n$-hexane, chloroform, ethyl acetate, and butanol. The hexane fraction (596 $\mathrm{mg}$ ) was further purified on a silica gel column $(2 \times 43 \mathrm{~cm})$ and eluted with $\mathrm{CHCl}_{3}-\mathrm{CH}_{3} \mathrm{OH}(10: 1, \mathrm{v} / \mathrm{v})$ to get compound 2 (128.5 $\mathrm{mg})$. The ethyl acetate fraction $(997.6 \mathrm{mg})$ was further separated on a silica gel column $(2.5 \times 44 \mathrm{~cm})$ with $\mathrm{CHCl}_{3}-\mathrm{CH}_{3} \mathrm{OH}(3: 1$, $\mathrm{v} / \mathrm{v})$ to get compound $3(13.5 \mathrm{mg})$. The butanol fraction $(1.3 \mathrm{~g})$ was subjected to silica gel column chromatography $(2.5 \times 45 \mathrm{~cm})$ and eluted with $\mathrm{CHCl}_{3}-\mathrm{CH}_{3} \mathrm{OH}(4: 1, \mathrm{v} / \mathrm{v})$ to get 27 fractions. Fractions 21 to 27 were purified on a Sephadex LH-20 column $(2 \times 36)$ eluted with $\mathrm{CHCl}_{3}-\mathrm{CH}_{3} \mathrm{OH}(3: 1, \mathrm{v} / \mathrm{v})$ to get compound 1 (11 mg) (Fig. 1). 


\section{Compound 1 (Tryptophan)}

Yellow powder. ${ }^{1} \mathrm{H}$ NMR $\left(\mathrm{CD}_{3} \mathrm{OD}, 400 \mathrm{MHz}\right) \delta 7.19$ $(1 \mathrm{H}, \mathrm{S}), \delta 7.11(1 \mathrm{H}, d d, J=7.3), \delta 7.05(1 \mathrm{H}, t, J=7.3), \delta 7.70(1 \mathrm{H}$, $d, J=8.2), \delta 7.36(1 \mathrm{H}, d, J=8.2), \delta 3.86(1 \mathrm{H}, d d, J=9.6,3.6 \mathrm{~Hz})$, $\delta 3.52(1 \mathrm{H}, d d, J=4.1,15.1 \mathrm{~Hz}), \delta 3.52(1 \mathrm{H}, d d, J=9.6,15.1 \mathrm{~Hz})$; 13C NMR (CD3OD, $400 \mathrm{MHz}) \delta 125.2$ (C-2), 109.6 (C-3), 122.8 (C-4), 120.2 (C-5), 119.4 (C-6), 112.5 (C-7), 138.5 (C-8), 128.6 (C-9), 28.6 (C-10), 56.8 (C-11), 174.6 (C-12) (Table 1).

Table 1: NMR spectroscopic data for compound $\mathbf{1}$ (400 $\mathrm{MHz} \mathrm{CD}_{3} \mathrm{OD}$ ).

\begin{tabular}{ccc}
\hline & \multicolumn{1}{c}{ compound 1 } \\
\cline { 2 - 3 } No. & $\boldsymbol{\delta} \mathbf{H}(\mathbf{i n t}, \mathbf{m u l t i}, \mathbf{J} \mathbf{H z})$ & $\boldsymbol{\delta} \mathbf{C}(\mathbf{p p m})$ \\
\hline 2 & $7.19(1 \mathrm{H}, s)$ & 125.2 \\
3 & $7.11(1 \mathrm{H}, d d, 7.3)$ & 109.6 \\
4 & $7.05(1 \mathrm{H}, t, 7.3)$ & 122.8 \\
5 & $7.70(1 \mathrm{H}, d, 8.2)$ & 120.2 \\
6 & $7.36(1 \mathrm{H}, d, 8.2)$ & 119.4 \\
7 & & 112.5 \\
8 & & 138.5 \\
9 & $3.86(1 \mathrm{H}, d d, 9.6,3.6)$ & 128.6 \\
10 & $3.52(1 \mathrm{H}, d d, 4.1,15.1)$ & 28.6 \\
11 & $3.52(1 \mathrm{H}, d d, 9.6,15.1)$ & 56.8 \\
12 & & 174.6 \\
\hline
\end{tabular}

\section{Compound 2 (Linoleic acid)}

Yellow powder. ${ }^{1} \mathrm{H}$ NMR $\left(\mathrm{CDCl}_{3}, 400 \mathrm{MHz}\right) \delta 2.34(2 \mathrm{H}$, $\mathrm{t}, J=7.5), \delta 1.63(2 \mathrm{H}, m), \delta 1.30(m), \delta 2.04(2 \mathrm{H}, m), \delta 5.36$ $(1 \mathrm{H}, m), \delta 5.36(1 \mathrm{H}, m), \delta 2.79(2 \mathrm{H}, m), \delta 5.36(1 \mathrm{H}, m), \delta 5.36$ $(1 \mathrm{H}, m), \delta 1.30(m), \delta 0.87(3 \mathrm{H}, t, J=6.4) ;{ }^{13} \mathrm{C} \mathrm{NMR}\left(\mathrm{CDCl}_{3} 400\right.$ $\mathrm{MHz}) 179.5$ (C-1), 34.3 (C-2), 24.9 (C-3), 29.2 29.8(C-5 C6), 27.3 (C-8), 130.1 (C-9), 128.2 (C-10), 25.7 (C-11), 128.0 (C-12), 130.3 (C-13), 27.3 (C-14), 29.3 (C-15), 32.0 (C-16), 22.8 (C-17), 14.2 (C-18) (Table 2).

\section{Compound 3 (Adenine)}

Yellow powder. ${ }^{1} \mathrm{H}$ NMR ( $\left.\mathrm{CD}_{3} \mathrm{OD}, 400 \mathrm{MHz}\right) \delta 8.10$ $(1 \mathrm{H}, s), \delta 7.09(1 \mathrm{H}, s) ;{ }^{13} \mathrm{C}$ NMR $\left(\mathrm{CD}_{3} \mathrm{OD}, 400 \mathrm{MHz}\right) \delta 155.8(\mathrm{C}-$ 1), 152.3 (C-2), 150.2 (C-3), 13.8.8 (C-4), 118.4 (C-5) (Table 3).

\section{Total polyphenol content and antioxidant activity}

Total polyphenol content was determined by the oxidation of phenolic compounds by a mix of phosphotungstic and phosphomolybdic acids in a base medium, producing blue acids of tungsten and molybdenum. Absorbance was then read at $765 \mathrm{~nm}$. The total polyphenol content was expressed as $\mathrm{mg}$ gallic acid equivalents. Each assay was performed in triplicate (Singleton et al., 1965). Total flavonoid content was determined by aluminum trichloride method using quercetin as a reference. $125 \mu \mathrm{l}$ of the extract is mixed with $75 \mu \mathrm{l}$ of a $5 \% \mathrm{NaNO}_{2}$ solution. The mixture was allowed to stand for $6 \mathrm{~min}$, before $150 \mu \mathrm{l}$ of aluminum trichloride $(10 \%)$ was added and incubated for $5 \mathrm{~min}$. Finally, $750 \mu \mathrm{l}$ of $1 \mathrm{M} \mathrm{NaOH}$ was added and the final volume was adjusted to $2.5 \mathrm{ml}$ with distilled water. After $15 \mathrm{~min}$ of incubation, the mixture turned to pink and the absorbance was measured at $510 \mathrm{~nm}$. The total flavonoid content was expressed as mg quercetin equivalents. The antioxidant activity of the extract was measured according to the method described by Bracca et al. with slight alterations. The reaction mixture consisted of $0.1 \mathrm{ml}$ extract with $0.2 \mathrm{ml}$ 2,2-diphenyl-1-picrylhydrazyl (DPPH) solution $(0.15 \mathrm{mM}$ in $80 \%$ methanol solution). The mixture was shaken strongly and left to stand for $30 \mathrm{~min}$ at room temperature in the dark. Ascorbic acid was taken as positive control. The absorbance was measured at $517 \mathrm{~nm}$ and the percent of inhibition was calculated.

$\mathrm{DPPH}$ Scavenging activity $(\%)=\left[1-\left\{\right.\right.$ sample $_{\mathrm{ABS}}-$ blank $\left._{\mathrm{ABS}}\right) /$ control $\left.\left._{\mathrm{ABS}}\right\}\right] \times 100$.

Table 2: NMR spectroscopic data for compound 2 (400 $\mathrm{MHz} \mathrm{CDCl}_{3}$ ).

\begin{tabular}{ccc}
\hline \multirow{2}{*}{ No. } & \multicolumn{1}{c}{ compound 2 } \\
\cline { 2 - 3 } & $\boldsymbol{\delta H}$ (int, multi, J Hz) & $\mathbf{\delta C}(\mathbf{p p m})$ \\
\hline 1 & $2.34(2 \mathrm{H}, t, 7.5)$ & 179.5 \\
3 & $1.63(2 \mathrm{H}, m)$ & 34.3 \\
4 & & 24.9 \\
5 & & \\
6 & $1.30(m)$ & $29.2 \sim 29.8$ \\
7 & & \\
8 & & 27.3 \\
9 & $2.04(2 \mathrm{H}, m)$ & 130.1 \\
10 & $5.36(1 \mathrm{H}, m)$ & 128.2 \\
11 & $5.36(1 \mathrm{H}, m)$ & 25.7 \\
12 & $2.79(2 \mathrm{H}, m)$ & 128.0 \\
13 & $5.36(1 \mathrm{H}, m)$ & 130.3 \\
14 & $5.36(1 \mathrm{H}, m)$ & 27.3 \\
15 & & 29.3 \\
16 & $1.30(\mathrm{~m})$ & 32.0 \\
17 & & 22.8 \\
18 & & 14.2 \\
\hline
\end{tabular}

Table 3: NMR spectroscopic data for compound 3 (400 $\left.\mathrm{MHz} \mathrm{CD}_{3} \mathrm{OD}\right)$.

\begin{tabular}{ccc}
\hline \multirow{2}{*}{ No. } & \multicolumn{2}{c}{ compound 3 } \\
\cline { 2 - 3 } & $\boldsymbol{\delta H}(\mathbf{i n t}, \mathbf{m u l t i}, \mathbf{J} \mathbf{H z})$ & $\boldsymbol{\delta C}(\mathbf{p p m})$ \\
\hline 1 & & 155.8 \\
2 & $8.10(1 \mathrm{H}, s)$ & 152.3 \\
3 & & 150.2 \\
4 & $7.09(1 \mathrm{H}, s)$ & 138.8 \\
5 & & 118.4 \\
\hline
\end{tabular}

\section{Cell viability assay}

Human dermal fibroblast (HDFn) cells were cultured in the Dulbecco's Modified Eagle Medium (DMEM) with 10\% fetal 
bovine serum (FBS), penicillin (100 units/ml) and streptomycin sulfate $(100 \mu \mathrm{g} / \mathrm{ml})$ growth medium in a humidified atmosphere of $37^{\circ} \mathrm{C}, 5 \% \mathrm{CO}_{2}$. The cytotoxicity assay was based on the cleavage of the yellow tetrazolium salt to form an orange formazan dye by active cells (Mosmann et al., 1983). Firstly, cells were cultured in 96-well plate $\left(1 \times 10^{4}\right.$ cells/well $)$ and kept in $\mathrm{CO}_{2}$ incubator $\left(37^{\circ} \mathrm{C}\right.$ with $5 \% \mathrm{CO}_{2}$ ) overnight for complete adhering to the plate. After incubation for 24 hours, MTT(3-(4,5-Dimethylthiazol-2-yl)-2,5diphenyltetrazolium bromide) reagent was added and the media were removed in 4 hours. Pigments were dissolved in DMSO and the absorbance was measured at $450 \mathrm{~nm}$.

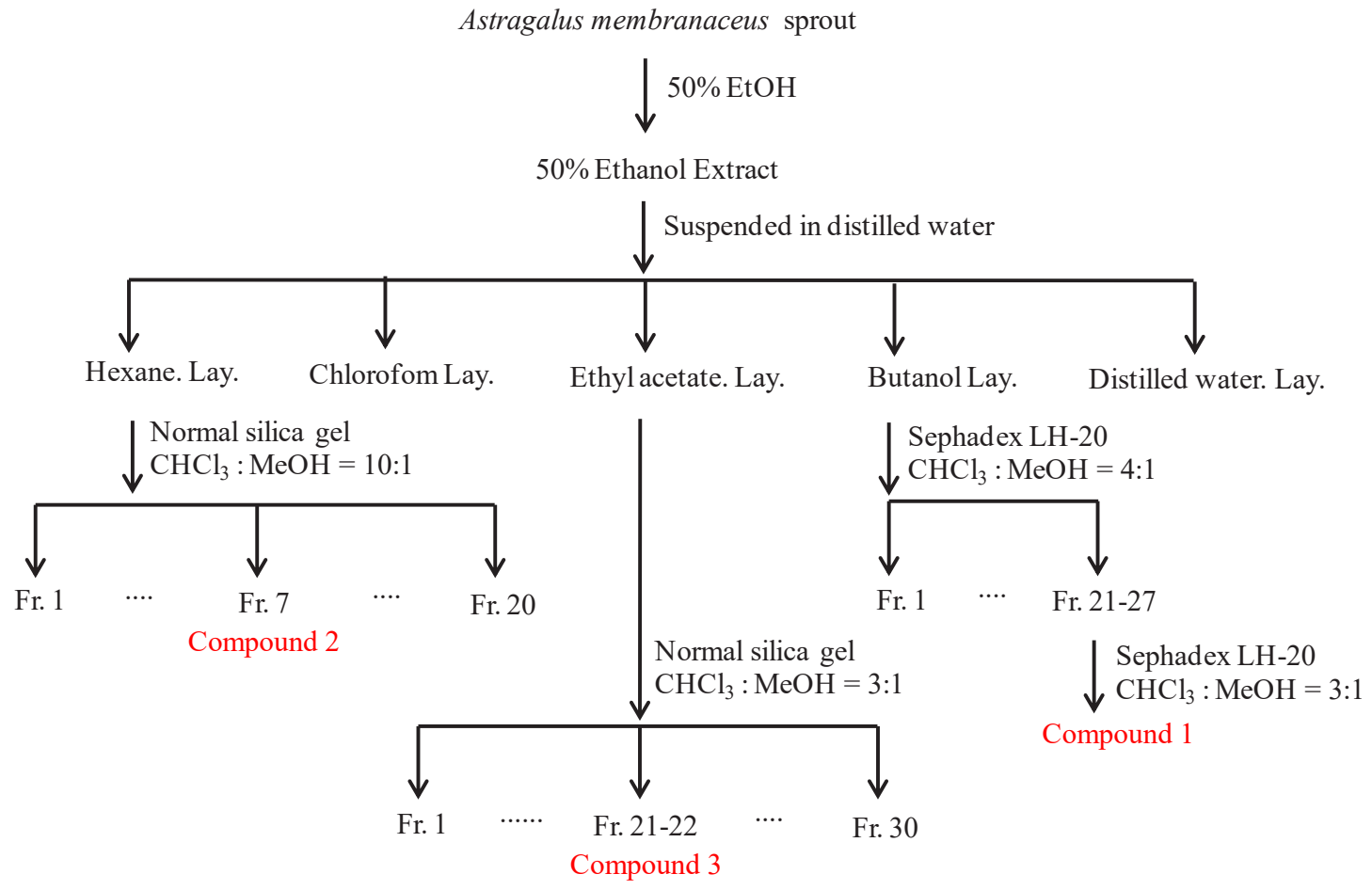

Fig. 2: Isolation scheme of the compounds 1, 2 and $\mathbf{3}$ from the extract of hwanggi sprouts.<smiles>NC(Cc1c[nH]c2ccccc12)C(=O)O</smiles>

Compound 1. Tryptophan<smiles>Nc1ncnc2nc[nH]c12</smiles><smiles>CCCCC/C=C\C/C=C\CCCCCCCC(=O)O</smiles>

Compound 3. Adenine

Compound 2. Linoleic acid

Fig. 3: Chemical structures of compounds 1, 2 and $\mathbf{3}$ isolated from hwanggi sprouts. 

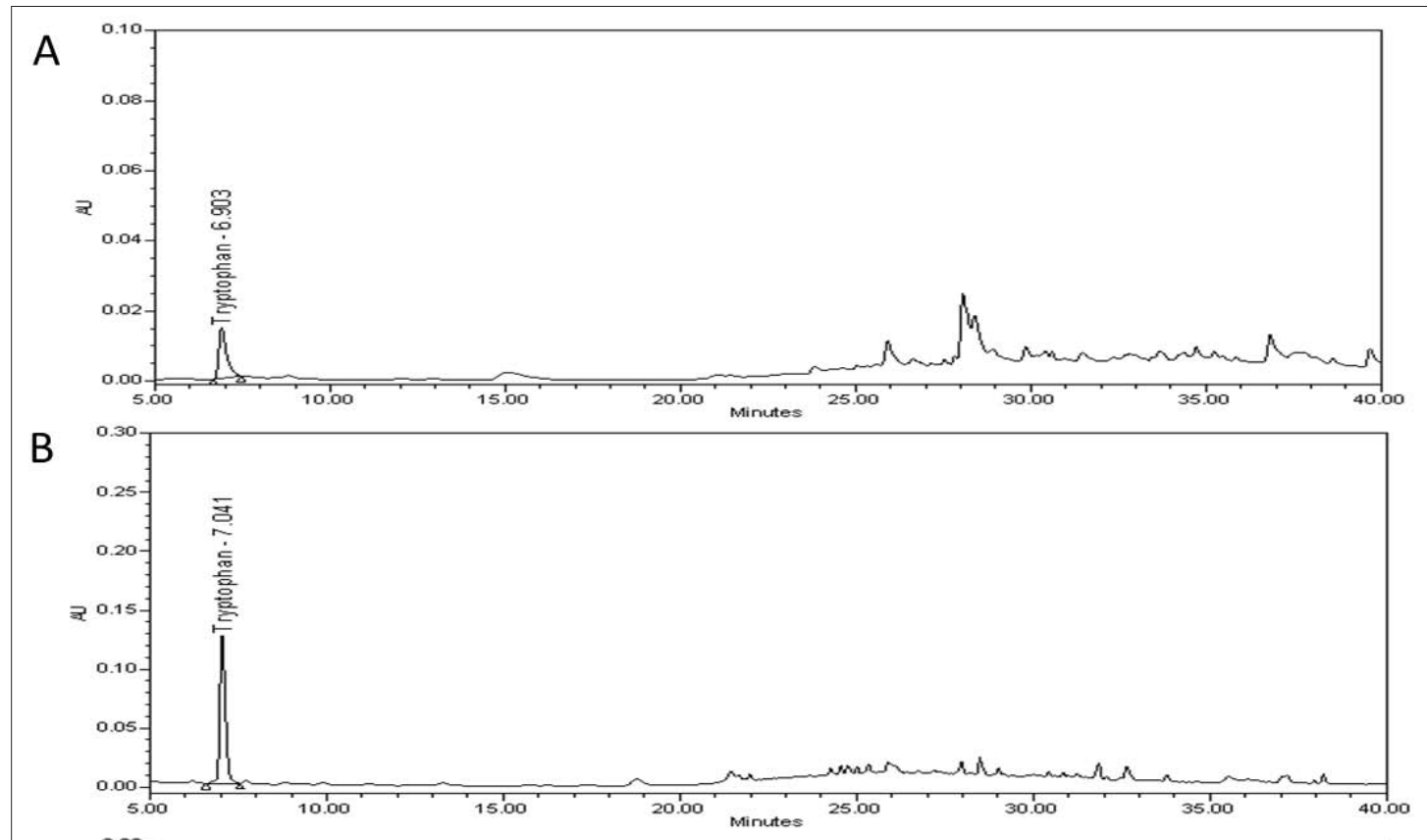

C
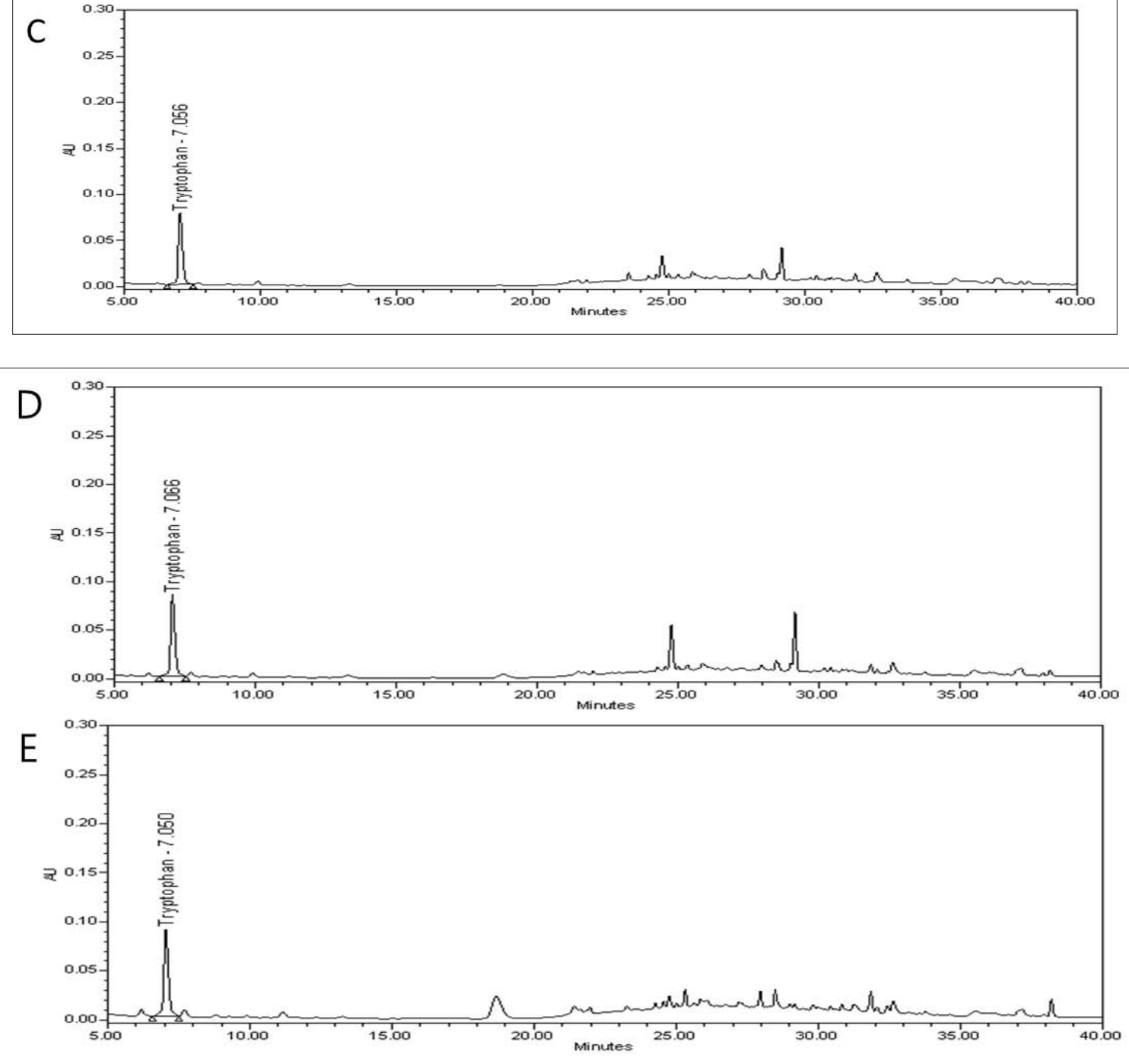

Fig. 4: HPLC profile of hwanggi sprouts extracts. A, isolated tryptophan; B, dark; C, white; D, red; E, blue. 


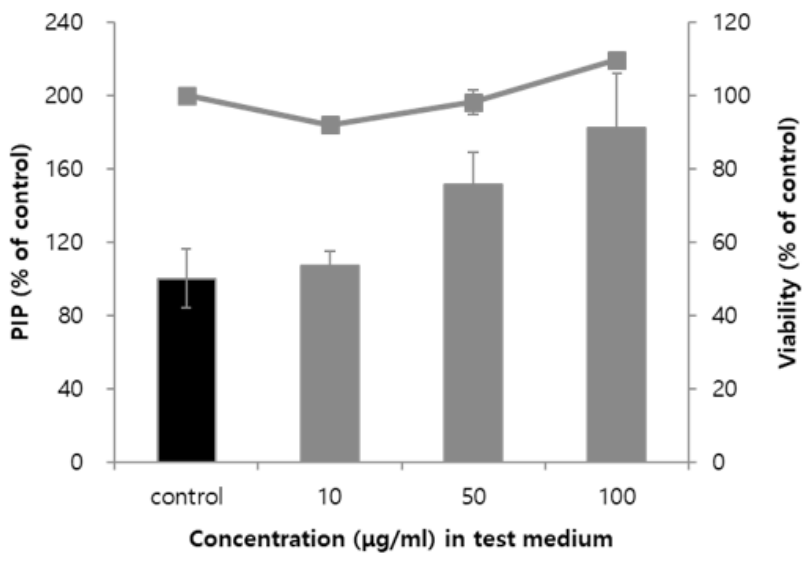

Fig. 5: Effect of the tryptophan on collagen synthesis and cell toxicities. Black and grey bars indicate the levels of PIP and the lines indicate cell viability.

\section{Determination of the amount of procollagen type $1 \mathrm{C}$-peptide (PIP)}

The cell suspension was transferred from the $10 \mathrm{~cm}^{2}$ plate into a 24 -well plate $\left(5 \times 10^{4}\right.$ cells/well $)$ for type 1 procollagen assay and incubated in $\mathrm{CO}_{2}$ incubator $\left(37^{\circ} \mathrm{C}, 5 \% \mathrm{CO}_{2}\right)$. After incubation, hwanggi sprout extract or each isolated compound was added to the plate in serum-free DMEM which kept in $\mathrm{CO}_{2}$ incubator $\left(37^{\circ} \mathrm{C}, 5 \% \mathrm{CO}_{2}\right)$ for 24 hours. The supernatants were gathered after a centrifugation at $13,000 \mathrm{rpm}$ in $4^{\circ} \mathrm{C}$ for $20 \mathrm{~min}$. The amount of PIP was measured according to the supplier's instructions (MK101, Takara, Japan).

\section{Statistical analysis}

Experimental data from more than triplicate are shown as means \pm standard deviations (SD).

\section{RESULTS}

To know the optimal growth conditions, total polyphenol content and antioxidant activity were assessed in the extracts of hwanggi sprouts grown under different light conditions, as shown in Table 4. The highest level of total polyphenols $(0.34 \pm 0.002$ $\mathrm{mg} / \mathrm{ml}$ ) was found in the white light sample, which also showed best antioxidant activity in a dose-dependent manner with $\mathrm{SC}_{50}$ value of $18 \%$. Then they were subjected to PIP assays, examining a cosmetic efficacy (Fig. 1). They showed enhanced collagen synthesis by HDFn cells at all conditions, while those grown under red and blue had slightly higher activity than the others.

A phytochemical isolation process was performed on hwanggi sprouts extracts to dissect the biologically active components (Fig. 2). In the series of fractions, pro-collagen synthesis activity was confirmed in the EtOAc, hexane and $n$-butanol fractions. From the $n$-butanol fraction, compound 1 (11 mg) was isolated and identified as tryptophan. Compound $2(128.5 \mathrm{mg})$ isolated from the EtOAc layer was linoleic acid and Compound 3 (13.5 $\mathrm{mg}$ ) isolated from the $n$-butanol layer was adenine. Compounds 1 and 3 were detected at 260-280 nm with the 8 to 9 -day-old sprouts (Fig. $3 \& 4$ ), but not detected in the adult root extract (data not shown). These compounds may appear at a certain period after germination, but not be contained in adult roots as much. The amount of tryptophan in the extracts was affected by light conditions and was higher in the darkness than the others (Fig. 4, Table 5). Isolated linoleic acid and adenine did not increase pro-collagen synthesis (not shown). On the other hand, isolated tryptophan increased pro-collagen synthesis, confirming that tryptophan is one of the active components of the sprouts (Fig. 5).

Table 4: Total polyphenol content and antioxidant activity of hwanggi sprouts grown under different light conditions.

\begin{tabular}{cccc}
\hline $\begin{array}{c}\text { Light } \\
\text { conditions }\end{array}$ & $\begin{array}{c}\text { Total } \\
\text { polyphenols } \\
(\mathbf{m g} / \mathbf{m L})\end{array}$ & $\begin{array}{c}\text { Total } \\
\text { flavonoids } \\
\mathbf{( m g / m L )}\end{array}$ & $\begin{array}{c}\text { DPPH Scavenging } \\
\text { activity } \\
\left.\mathbf{( S C}_{\mathbf{5 0}}, \mathbf{\%}\right)\end{array}$ \\
\hline Dark & $0.23 \pm 0.004$ & $0.04 \pm 0.007$ & $77 \pm 0.01$ \\
White & $0.34 \pm 0.002$ & $0.07 \pm 0.003$ & $18 \pm 0.007$ \\
Red & $0.22 \pm 0.015$ & $0.03 \pm 0.013$ & $51 \pm 0.003$ \\
Blue & $0.24 \pm 0.002$ & $0.01 \pm 0.002$ & $84 \pm 0.007$ \\
\hline
\end{tabular}

Table 5: Quantification of tryptophan in hwanggi sprouts extracts.

\begin{tabular}{cc}
\hline Light conditions & Tryptophan $(\mu / \mathbf{m L})$ \\
\hline Red & 3,770 \\
Blue & 4,088 \\
Dark & 6,247 \\
White & 4,555 \\
\hline
\end{tabular}

\section{DISCUSSION}

We here report that $A$. membranaceus sprouts grown under a controllable environment could be developed as a novel anti-aging agent for skin care products. As far as we know, this is the first report of research on $A$. membranaceus sprouts and the first identification of plant tryptophan as a collagen inducer, although A. membranaceus is an important and well-studied medicinal herb (Tzu et al., 2014). The cosmetic application has been made by peptides hydrolyzed from its adult roots, inhibiting expressions of MMPs in human dermal fibroblasts (Sun et al., 2014).

In this study, we demonstrated that tryptophan from hwanggi sprout extract can play a role in collagen synthesis of HDFn cells. Collagen does not contain a particularly high amount of tryptophan and there has been no report of the collagen-inducing activity of tryptophan. This result was unexpected but confirmed by the same activity with the commercially available tryptophan (Sigma Aldrich, data not shown). The detailed mechanism of the collagen induction by tryptophan which is not a major constituent of collagen is of high interest and needs more work to dissect from the sensing of external tryptophan and to the induction of Coll genes by HDFn cells. But, tryptophan may not be a sole factor for these activities because the condition producing most of the tryptophan (dark) is not the same as the one for highest activity (red). It is more reasonable that multiple compounds in hwanggi sprouts act together to induce collagen synthesis of skin cells.

Conclusively, hwanggi sprouts grown under different light conditions showed distinct activities, and more specifically, one of its active compounds, tryptophan can play a role in the antiwrinkle effect of cosmetic products. In addition, this is another example that indoor cultivation system for sprouts can optimize and standardize raw material production, which is a critical step in the natural product industry (Chang et al., 2014). 


\section{REFERENCES}

Braca A, Tommasi ND, Bari LD. Antioxidant Principles from Bauhinia Terapotensis. Journal of Natural Products, 2001; 64:892-895.

Chang MS, Jung US, Lee SM, Nam TG, Park JI, Kang MH, Kim DO, Hwang JS, Eom SH. 8-hydroxyarctigenin Isolated from Safflower Sprouts Inhibits Melanogenesis of Melan-a Cells and Light Quality during the Sprout Growth Determines the Compound Yield. Hort. Environ. Biotechnol, 2014; 55(2):97-102.

Cho WCS, Leung KN. In vitro and in vivo anti-tumor effects of Astragalus membranaceus. Cancer Lett, 2007; 252:43-54.

Fisher GJ, Kang S, Varan J, Bata-Csorgo Z, Wan Y, Datta S, Voorhees JJ. Mechanisms of photoaging and chronological skin aging. Arch. Dermatol, 2002; 138:1462-1470.

Kim JH, Kim MH, Yang G, Huh Y, Kim SH, Yang WM. Effects of topical application of Astragalus membranaceus on allergic dermatitis. Immunopharmacol Immunotoxicol, 2013; 35(1):151-156.

Kwon HJ, Hwang J, Lee SK, Park YD. Astragaloside content in the periderm, cortex, and xylem of Astragalus. membranaceus root. J. Nat. Med, 2013; 67:850-855

Luo X, Huang P, Yuan B, Liu T, Lan F, Lu X, Dai L, Liu Y, Yin H, Astragaloside IV enhances diabetic wound healing involving upregulation of alternatively activated macrophages. Int Immunopharmacol, 2016; $34: 22-28$.

Lei H, Wang B, Li WP, Yang Y, Zhou AW, Chen MZ. Anti-aging effect of astragalosides and its mechanism of action. Acta Pharmacol Sin, $2003 ; 2: 230-234$

Ma XQ, Duan JA, Zhu DY, Dong TX, Tsim KWK. Species identification of Radix Astragali (Huangqi) by DNA sequence of its 5S-rRNA spacer domain. Phytochemistry, 2000; 54:363-368.

Mi YY. A Study on Peanut Spouts Extract as the Anti-oxidant Activity and the Skin Whitening Cosmetic Ingredients. Korean Society for Biotechnology and Bioengineering Journal, 2016; 31(1):14-19.

Mosmann T. Rapid Colorimetric Assay for Cellular Growth and Survival: Application to Proliferation and Cytotoxicity Assays. Journal of Immunological Methods, 1983; 65:55-63.
Lovell CR, Smolenski KA, Duance VC, Light ND, Young S, Dyson M. Type I and III collagen content and fibre distribution in normal human skin during ageing. Br J Dermatol, 1987; 17:419-428.

Ren S, Zhang H, Mu Y, Sun M, Liu P. Pharmacological effects of Astragaloside IV: A literature review. J Tradit Chin Med, 2013; 33:413-416.

Sher GJ, Wang ZQ, Datta SC, Varani J, Kang S, Voorhees JJ. Pathophysiology of premature skin aging induced by ultraviolet light. $\mathrm{N}$ Engl J Med, 1997; 337:1419-1428.

Singleton VL, Joseph AR. Colorimetry of total phenolics with phosphomolybdic phosphotungstic acid reagents. American Journal of Enology and Viticulture, 1965; 16:144-158.

Sun KP, Pham VH, Hoang VL, Shao WY, Sang YB. Peptide Hydrolysates from Astragalus membranaceus Bunge Inhibit the Expression of Matrix Metalloproteinases in Human Dermal Fibroblasts. Korean Society for Biotechnology and Bioengineering Journal, 2014; 29:380-384.

Tzu SY, Hsiao LC, Wen CH, Yi MC, Chi CH, Mei CH. Astragalus membranaceus Improves Exercise Performance and Ameliorates ExerciseInduced Fatigue in Trained Mice. Molecules, 2014; 19:2793-2807.

Wang T. Bioactive cyclolanstane-type saponins from the stems of Astragalus membranaceus (Fisch.) Bge. var. mongholicus (Bge.) Hsiao J Nat Med, 2016; 70:198-206.

Zhang WD, Chen H, Zhang C, Liu RH, Li HL, Chen HZ. Astragaloside IV from Astragalus membranaceus shows cardioprotection during myocardial ischemia in vivo and in vitro. Planta Med, 2006; 72:48.

Zhang WJ, Hufnag P, Binder BR, Wojta J. Anti-inflammatory activity of astragaloside IV is mediated by inhibition of NF-kappaB activation and adhesion molecule expression. Thromb. Haemost, 2003; 90:904-914

How to cite this article:

Jeong SY, Moon MY, Ryu EK, Lee JS, Cha J. Identification of the Phytochemical Compounds and Their Type I Procollagen Induction in Astragalus membranaceus Sprouts Grown under Different Light Conditions. J App Pharm Sci, 2018; 8(06): 001007. 